\title{
Estudantes com Necessidades Educacionais Especiais nas Avaliaçóes em Larga Escala: Prova Brasil e ENEM ${ }^{1}$ \\ Students With SpeCial EDUCATIONAL NeEdS in LARGE-SCALE NATIONAL TESTING: PROVA BRASIL AND ENEM ${ }^{1}$
}

\author{
Mariana Cesar Verçosa SILVA² \\ Silvia Márcia Ferreira MELETTI ${ }^{3}$
}

\begin{abstract}
RESUMO: o presente estudo trata da escolarização de alunos com necessidades educacionais especiais, na rede regular de ensino do município de Londrina (PR), por meio da análise das avaliaçóes em larga escala. Especificamente, objetivou analisar a participação e o desempenho da referida população nas avaliaçōes: Prova Brasil e Exame Nacional do Ensino Médio (ENEM), nos anos de 2007 e 2008, e teve como base empírica os microdados dessas avaliaçôes disponibilizados pelo Instituto Nacional de Estudos e Pesquisa Educacionais Anísio Teixeira (INEP), segundo as variáveis: participação na prova, tipo de necessidade educacional especial, sexo, raça-etnia, idade e desempenho. Os resultados da pesquisa apontam que uma parcela significativa da populaçáo com necessidade educacional especial realizou o Exame Nacional do Ensino Médio (ENEM); entretanto, na Prova Brasil a participaçấo dos alunos com necessidades educacionais especiais foi mínima, o que reforça a ideia de ambiguidade entre discurso e prática inclusiva.
\end{abstract}

PALAVRAS-CHAVES: Educação Especial. Exame Nacional do Ensino Médio. Sistema Nacional de Avaliação da Educaçấo Básica. Inclusão Escolar.

\begin{abstract}
This study addresses the education of students with special educational needs in mainstream education in Londrina, Paraná, by analyzing large-scale national academic achievement assessments. Specifically the study aimed to analyze the participation and performance of this group of students in the Prova Brasil and ENEM tests for the years 2007 and 2008. The empirical basis for the study were microdata from the tests provided by the Instituto Nacional de Estudos e Pesquisa Educacionais Anísio Teixeira (INEP), within the following variables: participation in the test, type of special educational need, sex, race-ethnicity, age and performance. The results indicate that a significant portion of the population with special educational needs underwent the ENEM, however the participation of students with special educational needs in the Prova Brasil was minimal, reinforcing the idea of ambiguity between inclusive discourse and practice.
\end{abstract}

KEYWORDS: Special Education. National Evaluation of Basic Education. School Inclusion. National Education Assessment.

\section{INTRODUÇÁO}

O presente estudo analisa a participação de alunos com necessidades educacionais especiais (NEE) nas avaliaçóes em larga escala, na rede regular de ensino do município de Londrina (PR). Especificamente, analisamos a frequência e o desempenho desta populaçáo na Prova Brasil e no Exame Nacional do Ensino Médio (ENEM), a partir dos dados oficiais do poder público.

As práticas das avaliações em massa como meio de mensurar a qualidade da educação básica brasileira acontece desde a década de 1920, mas é com a Reforma do Estado, na década

\footnotetext{
${ }^{1}$ Este artigo constitui um recorte da dissertação de Mestrado em Educação intitulada "Avaliação em larga escala de alunos com necessidades educacionais especiais no município de Londrina - PR”, financiada pela CAPES/Observatório da Educação.

2 Pedagoga, Especialista em Educaçăo Especial pela UNOPAR, Mestre em Educação pela Universidade Estadual de Londrina, Londrina, Paraná, Brasil. nana_vercosa@hotmail.com

${ }^{3}$ Docente do Departamento de Educação e do Programa de Pós-Graduação em Educação da Universidade Estadual de Londrina, Londrina, Paraná, Brasil. smeletti@gmail.com
} 
de 1990, que se consolidam, com marcada influência dos parâmetros de "sucesso educacional" internacionais. Observa-se a padronização de um sistema avaliativo educacional de cunho meritocrático, que aumenta o seu controle social, por meio de tal processo avaliativo, já que utiliza as avaliaçóes em larga escala como parâmetro para o financiamento do setor educacional. "A lógica gerencial lança mão de um arcabouço de avaliaçôes de políticas públicas focadas exclusivamente nos resultados, prestando-se como parâmetros do financiamento em educação" (ZANARDINI, 2008, p. 30b). Logo, as práticas das avaliaçóes em larga escala são acentuadas a partir da criação e vigência dos fundos: Fundo Nacional de Desenvolvimento da Educação (FUNDEB) e Fundo de Manutenção e Desenvolvimento do Ensino Fundamental e Valorização do Magistério (FUNDEF). A postura do Estado brasileiro segue a seguinte ideia: a sociedade e os educadores foram atendidos no que concerne à reivindicação histórica da ampliação de acesso à educação, mas, as escolas, alunos e professores, em contrapartida, devem prestar conta de tal investimento, por meio dos resultados obtidos da avaliação em larga escala.

$\mathrm{Na}$ conjuntura atual, o Estado considera o processo nacional de avaliação em larga escala: Prova Brasil, Exame Nacional do Ensino Médio (ENEM) e o Exame Nacional de Desempenho de Estudantes (ENADE) como indicador da qualidade do sistema educacional brasileiro. De acordo com o Ministério da Educação a Prova Brasil (BRASIL, 2012a), é uma avaliação diagnóstica, em larga escala, utilizada desde 2005, para avaliar o Ensino Fundamental no país, implementar políticas públicas educacionais e direcionar recursos técnico, pedagógico e financeiro. A aplicação da Prova Brasil ocorre a cada dois anos com alunos do sistema público, que estão na quarta e oitava série, ou quinto e nono ano do Ensino Fundamental, a partir de testes padronizados de língua portuguesa e matemática.

Outro modelo de avaliação em larga escala é o Exame Nacional do Ensino Médio (ENEM), o Ministério da Educação (MEC), juntamente com o Governo Federal, apresentou no ano de 1998 a proposta de avaliar anualmente o final da escolaridade básica no país, a partir do Exame Nacional do Ensino Médio, o ENEM. Com o objetivo de avaliar competências e habilidades individuais, embasadas em questôes interdisciplinares, que explicitem situações cotidianas e uma redação. Atualmente, a avaliação é utilizada por algumas universidades como processo de seleção para o ensino superior (substituindo o vestibular), bem como serve de critério para a distribuição de bolsas integrais e parciais no Programa Universidade para TodosProUni (BRASIL, 2012b).

O discurso oficial do poder público revela a ideia de excelência da avaliação sistêmica, bem como levanta a hipótese de que tal instrumento é capaz de transformar a educação. Entretanto, cabe evidenciar que os discursos aparentemente democráticos e legítimos "de melhoria da qualidade", "acesso efetivo aos conhecimentos escolares", "apoio técnico, pedagógico e financeiro”, possuem um forte caráter ideológico. Na verdade, a avaliação sistêmica é dotada de açóes centralizadoras e antidemocráticas, que naturalizam as desigualdades sociais, por meio da manutenção do controle do Governo sob os sistemas de ensino. De fato, a avaliação em larga escala vem sendo utilizada como tecnologia (controle, eficiência, eficácia) para produzir informaçóes e prestar contas sobre o sistema educacional: professores, alunos, gestores e escola. Isto significa que tal tecnologia não passa de um conhecimento aplicado para que as pessoas e escolas se conformem com o sistema social, favorecendo assim, a perpetuação da ideologia (controle e da dominação) que sustenta a avaliação em larga escala. (SASS; MINHOTO, 2011). 
Neste mesmo contexto político, temos a ampliação do processo de universalização da Educação Básica, com a adoção, por parte do poder público brasileiro, de uma proposta de sistema educacional inclusivo (KASSAR; MELETTI, 2012). Isso impacta sobremaneira a educação oferecida aos alunos com NEE, especificamente no que se refere ao acesso desta população ao sistema regular de ensino. Meletti e Bueno (2010), ao compararem os números de matrículas de alunos com NEE na Educação Básica brasileira, do ano de 2009, com os de 2000, constataram um aumento de 58\% das matrículas.

Por outro lado, para que haja o processo de inclusão, além do acesso à escola regular, a permanência e a inserção em processos de escolarização efetivos, o que pressupóe sua participação ativa no ambiente escolar. No que se refere aos alunos com NEE, é de se supor que sua inserção no sistema regular de ensino deva ser conduzida de modo a garantir que seu processo de escolarização contemple todas as etapas e atividades daqueles que não possuem tal condição. Assim, analisar o processo de inclusão desta população na escola implica conhecer como se dá sua participação no cotidiano escolar, inclusive, e principalmente, naquilo que diz respeito aos processos que subsidiam as análises do sistema educacional brasileiro, como é o caso das avaliaçóes em larga escala.

\section{Método}

Os indicadores sociais, constituídos por meio de estatísticas públicas, utilizadas para traduzir um determinado aspecto da realidade social, são frequentemente utilizados para avaliar os avanços e os retrocessos da sociedade contemporânea, bem como para apontar o sucesso ou não das políticas públicas. Podem ser agrupados em temáticas: demografia, saúde, renda e pobreza, habitação, qualidade de vida, educação e entre outros (JANNUZZI, 2006). No Brasil, e coleta e divulgação de dados estatísticos específicos sobre educação, é de responsabilidade do Instituto Nacional de Estudos e Pesquisa Educacionais Anísio Teixeira (INEP).

O presente estudo teve como base o levantamento dos indicadores sociais de caráter estatístico-educacionais disponibilizados pelo INEP, a partir de dados coletados, pelo sistema Educacenso em âmbito nacional. De acordo com o INEP, estes indicadores educacionais, disponíveis por meio de "microdados" ${ }^{4}$, estão acessíveis a todos e podem ser baixados pela Internet por meio de seu sítio na internet, podendo ser salvos em dispositivos remotos (pen drives, mídias ou discos rígidos externos) ou no computador. Tais microdados oferecem informaçóes detalhadas acerca das matrículas de alunos, professores e escolas, além de dados relativos ao desempenho dos alunos, como o SAEB, Prova Brasil, ENEM e ENADE. Apesar da indicação de que os microdados são acessíveis a todos, é preciso destacar que o acesso não é simples. Além da necessidade de software específico, é preciso computadores que comportem os bancos de dados. A seguir, o procedimento de coleta dos dados será apresentado de modo detalhado evidenciando a complexidade do processo.

\footnotetext{
4 "Microdados consistem no menor nível de desagregação dos dados de uma pesquisa, retratando, sob a forma de códigos numéricos, o conteúdo dos questionários, preservado o sigilo das informaçóes. Os microdados possibilitam aos usuários, com conhecimento de linguagens de programação ou softwares de cálculo, criar suas próprias tabelas”. Disponível em: (<http://www.ibge.gov. br>). Acesso em: 12 nov. 2012. Leitura de arquivos por meio da utilização dos softwares SAS e SPSS”. Disponível em: (<http:// dados.gov.br/dataset/microdados-do-censo-escolar>). Acesso em: 12 nov. 2012.
} 


\subsection{Coleta dos dados}

Para chegar ao resultado das avaliaçóes dos alunos com NEE, utilizamos o software IBM SPSS Statistics (Statistical Package for the Social Science), um programa desenvolvido para realizar análises estatísticas.

Inicialmente, procuramos verificar se os questionários socioeconômico da Prova Brasil e do ENEM contemplavam alguma variável "apresenta Necessidades Educacionais Especiais". Observou-se que tal variável está presente apenas nos microdados do ENEM do ano de 2010 (BRASIL, 2012c). Apesar desta variável estar disponível apenas para este ano, ela por si só não foi suficiente para a obtençáo dos dados que precisávamos, porquanto constatamos que há algumas inconsistências entre o questionário do aluno e os gabaritos das provas.

Foi necessário, então, partir para outra tentativa: encontrar os alunos que fizeram as provas na base de dados do Censo Escolar por meio do número de matrícula e/ou código do aluno, no intuito de que estes códigos fossem os mesmos, para, assim, fazer o cruzamento (matrícula versus avaliação) e chegar aos dados esperados. Entretanto, nos deparamos com mais uma barreira: não havia equivalência entre os códigos do Censo Escolar e os da Prova Brasil e do ENEM, pois existe uma máscara que altera o número de matrícula, como garantia do sigilo dos dados dos alunos; além disto, este código é específico para cada edição da prova. Consequentemente, não foi possível localizar as avaliaçóes dos alunos NEE com base nos dados disponíveis nos bancos das avaliaçóes em larga escala e do Censo Escolar.

Entáo, foi preciso partir para um novo passo. Utilizamos tanto os dados do Censo Escolar dos anos de 2007 e 2008 (BRASIL,2012d) quanto os dados da Prova Brasil e do ENEM, por meio do procedimento descrito a seguir.

Em primeiro lugar, novamente utilizamos aquele programa com o intuito de isolar os dados relativos aos alunos com NEE, matriculados nas escolas do município de Londrina, que se encontram na quarta e oitava séries (para aqueles que fizeram a Prova Brasil) e do terceiro ano do Ensino Médio (para aqueles que fizeram o ENEM). Estas variáveis foram filtradas por um procedimento específico do software, a fim de selecionar, dentre as matrículas de todos os alunos paranaenses, apenas as matrículas que nos interessavam para a realização da pesquisa, excluindo todas as outras que não atendiam aos critérios adotados.

Logo após esta filtragem, foi possível obter diversas informaçóes sobre cada um dos alunos, tais como etapa e modalidade de ensino, tipo de Necessidade Educacional Especial, idade, sexo, raça-etnia, dia, mês e ano de nascimento, código de matrícula, código da escola, dependência administrativa da instituiçâo educacional, entre outras características. De posse desses dados, passamos a fazer o cruzamento destes com os dados encontrados no questionário socioeconômico da Prova Brasil e ENEM respondidos pelos próprios alunos.

Com as variáveis do Censo Escolar citadas acima, foi possível responder as quatro primeiras questóes do questionário da Prova Brasil do ano de 2007 (BRASIL, 2012e), a partir das características: sexo, raça-etnia, mês de nascimento e idade. Com relação ao questionário do ENEM de 2007 e 2008 (BRASIL,2012f), foram utilizadas as variáveis: sexo, raça-etnia, dia, mês e ano de nascimento. Com efeito, pudemos identificar aquilo que precisávamos: a participação dos alunos com NEE nas avaliaçóes e também o acesso aos gabaritos dessas avaliações. 
Embora tenhamos finalmente encontrado um procedimento que nos permitiu a coleta dos dados, é imprescindível mencionar que ele não estava isento de empecilhos. Encontramos, ao longo do processo, casos de "duplicidade": ao verificar as questóes do questionário com base nos dados do Censo Escolar, constatamos, em alguns casos, mais de um aluno com as mesmas características, ou seja, encontramos alunos do mesmo sexo, mesma raça, mesmo mês de nascimento e mesma idade. Nestes casos, como não foi possível efetuar a identificação dos dados do Censo com os da Prova Brasil ou ENEM, optamos por náo considerar estes casos e trabalhar com uma amostra menor.

Estas duplicidades estavam presentes na Prova Brasil de 2007 (BRASIL, 2012g) e no ENEM de 2008 (BRASIL, 2012h); na Prova Brasil de 2007 (BRASIL, 2012i), o caso de "duplicidade" ocorreu apenas nas avaliaçóes da quarta série. Por esta razão, a pesquisa foi pautada em uma amostra representativa de 69 alunos com NEE na referida etapa de ensino, excluindo da amostra os nove casos de duplicidade. Já no ENEM de 2008 (BRASIL, 2012j), houve um caso de duplicidade; assim, foi considerado o contingente de oito estudantes com NEE matriculados no terceiro ano do Ensino Médio.

Cumpre destacar que a ideia inicial da pesquisa era baixar e analisar todos os arquivos da Prova Brasil e do ENEM presentes no sítio do INEP no ícone microdados para download: SAEB (2005), Prova Brasil (2007 e 2009) e ENEM (2007, 2008, 2009 e 2010). Isso não foi possível, visto que a estrutura dos arquivos e os questionários aplicados nas avaliaçóes foram modificados a cada edição das avaliaçóes, impedindo a continuidade necessária para a sua organização e comparação.

\subsection{Análise dos Dados}

Os microdados do Censo Escolar de 2007 e 2008, da Prova Brasil de 2007 e do ENEM de 2007e 2008, coletados e divulgados pelo INEP foram analisados segundo: características do aluno (Necessidade Educacional Especial, sexo, raça-etnia e idade), participação na prova e desempenho.

Destaca-se que foram analisados os dados das avaliações apenas de alunos com NEE matriculados na rede pública de ensino, já que o (INEP) não divulga os microdados de escolas privadas.

\section{Resultados}

\subsection{ANO DE 2007}

Verificou-se a partir dos microdados do Censo Escolar de 2007 (BRASIL, 2012n), que no município de Londrina havia um total de 123.417 matrículas, sendo que 1.915 referiam-se a alunos com NEE. Dentre estes, 78 estavam matriculados na $4^{\mathrm{a}}$ série, 21 na $8^{\mathrm{a}}$ série e 13 no $3^{\circ}$ ano do Ensino Médio.

Dos 78 estudantes com Necessidades Educacionais Especiais presentes na $4^{\mathrm{a}}$ série no município, que poderiam realizar a Prova Brasil no ano de 2007, 63 encontram-se na rede pública e 15 na privada. Já na $8^{a}$ série, oito estudantes encontram-se na rede pública e 13 na privada. Já no 3o ano do Ensino Médio, todos estão matriculados na rede pública. Contudo, 
vale enfatizar que 11 alunos da referida etapa de ensino encontram-se matriculados em uma escola especial exclusiva para surdos, o Instituto Londrinense de Educação para Surdos (ILES), que está classificada no Censo Escolar com escola regular da rede estadual de ensino.

A Tabela 1 apresenta a distribuição dos alunos com Necessidades Educacionais Especiais que fizeram a avaliação: Prova Brasil e ENEM.

Tabela 1- Distribuição dos alunos com Necessidades Educacionais Especiais (NEEs) em relação à participação na Prova Brasil e Exame Nacional do Ensino Médio (ENEM).

\begin{tabular}{lccc}
\hline ALUNOS COM NEE & $4^{a}$ série & $8^{a}$ série & $3^{\circ}$ ano \\
\hline Com prova & 21 & 05 & 10 \\
Sem prova & 48 & 16 & 03 \\
Total & 69 & 21 & 13 \\
\hline
\end{tabular}

Fonte: Elaboração própria com base nas informaçôes extraídas dos microdados do Censo da Educação Básica, da Prova Brasil e do ENEM (MEC/INEP, 2007 e 2008).

Vale destacar que nesta tabela foram descartados os nove casos de duplicidade obtidos nas avaliaçóes da Prova Brasil; portanto, na $4^{\mathrm{a}}$ série, foi considerado apenas uma amostra de 69 alunos. Destes, 48 não fizeram a prova e 21 fizeram, o que equivale a dizer que, aproximadamente, três em cada 10 alunos com NEE no município realizaram a Prova Brasil.

Já na Prova Brasil da 8a série de 21 alunos com Necessidades Educacionais Especiais, cinco fizeram a prova e 16 são ausentes. Portanto, três em cada quatro estudantes com NEE não fizeram a Prova Brasil. No $3^{\circ}$ ano do Ensino Médio, de 13 alunos, 10 realizaram a prova, ou seja, aproximadamente três em cada quatro alunos realizaram o ENEM.

Observa-se, primeiro, a baixa incidência de matrículas nas séries analisadas. Dos 1.915 alunos com NEE, apenas 69 estavam matriculados na $4^{\mathrm{a}}$ série, 21 na $8^{\mathrm{a}}$ e 13 no $3^{\circ}$ ano do Ensino Médio. Meletti e Bueno (2011) mostram que a maioria das matrículas de alunos com NEE se concentra nos dois primeiros anos do Ensino Fundamental I e que isto pode indicar a não progressão desta população por todas as etapas de ensino.

Segundo, destaca-se o número de alunos com NEE que não participaram das provas, o que pode sustentar a análise de que não incentivo e/ou permissão para sua participação, haja vista os objetivos das avaliaçóes em larga escala e sua centralidade no financiamento da educação e no repasse de verbas à escola. Está subentendido que a participação pode impactar negativamente a nota geral da escola, diminuindo assim seus índices.

Cumpre destacar, ainda, que, dos 13 alunos matriculados no Ensino Médio, 12 estudavam em escola especial que, por ser reconhecida como escola da rede estadual de ensino, possui seriação e atribui grau de escolaridade. Contraditoriamente, observamos que a participação no ENEM, que pode possibilitar a continuidade dos estudos em nível superior, é sustentada por um espaço de ensino considerado segregado.

A Tabela 2 apresenta a caracterização (tipo de Necessidade Educacional Especial (NEE), gênero, raça, idade e desempenho) dos alunos com Necessidades Educacionais Especiais da 4a série do município de Londrina (PR), que fizeram a Prova Brasil no ano de 2007. 
Tabela 2 - Caracterização dos alunos com Necessidades Educacionais Especiais (NEEs) que realizaram a Prova Brasil na $4^{\mathrm{a}}$ série.

\begin{tabular}{lccccc}
\hline NEE & SEXO & RAÇA & IDADE & \multicolumn{2}{c}{ DESEMPENHO } \\
& & & & Língua Portuguesa & Matemática \\
\hline 1. def. auditiva & $\mathrm{M}$ & branca & 10 & 13 & 9 \\
2. baixa visão & $\mathrm{M}$ & branca & 10 & 13 & 0 \\
3. superdotaçáo & $\mathrm{M}$ & branca & 10 & 18 & 16 \\
4. superdotação & $\mathrm{F}$ & branca & 10 & 8 & 19 \\
5. TGD & $\mathrm{M}$ & parda & 13 & 9 & 3 \\
6. def. intelectual & $\mathrm{M}$ & parda & 15 & 5 & 9 \\
7. def. intelectual & $\mathrm{F}$ & náo dec. & 15 & 8 & 8 \\
8. def. múltipla & $\mathrm{M}$ & branca & 11 & 15 & 3 \\
9. TGD & $\mathrm{F}$ & parda & 11 & 14 & 8 \\
10. def. física & $\mathrm{F}$ & branca & 11 & 12 & 7 \\
11. baixa visão & $\mathrm{F}$ & branca & 10 & 16 & 12 \\
12. superdotaçáo & $\mathrm{F}$ & parda & 10 & 15 & 19 \\
13. def. física & $\mathrm{M}$ & branca & 10 & 11 & 8 \\
14. TGD & $\mathrm{M}$ & preta & 10 & 11 & 11 \\
15. surdez & $\mathrm{M}$ & branca & 12 & 9 & 8 \\
16. TGD & $\mathrm{M}$ & branca & 11 & 9 & 11 \\
17. TGD & $\mathrm{M}$ & branca & 14 & 8 & 8 \\
18. def. intelectual & $\mathrm{F}$ & parda & 16 & 7 & 14 \\
19. def. física & $\mathrm{M}$ & branca & 11 & sem nota & sem nota \\
20. def. intelectual & $\mathrm{M}$ & indígena & 14 & 5 & 5 \\
21. def. intelectual & $\mathrm{M}$ & năo decl. & 16 & & 3 \\
\hline
\end{tabular}

Fonte: Elaboração própria com base nas informaçóes extraídas dos microdados do Censo da Educaçáo Básica e da Prova Brasil (MEC/INEP, 2007).

Dentre os 21 alunos que realizaram a prova, não foi possível notar uma incidência significativa de uma Necessidade Educacional Especial em detrimento de outra. Os alunos que fizeram a avaliação apresentam condiçóes variadas, tais como: deficiência auditiva, surdez, deficiência múltipla, deficiências física e intelectual, baixa visão, superdotação, deficiência física, deficiência intelectual e transtornos globais do desenvolvimento. Com relação ao sexo, há uma aluna do sexo feminino para cada dois do sexo masculino. Proporçáo distinta das estimativas demográficas divulgadas pelo IBGE (2012), que mostram incidência equivalente entre homens e mulheres que apresentam algum tipo de deficiência. Isso pode significar duas possibilidades: mulheres com NEE têm menos acesso à escola e/ou homens são mais identificados como alunos com NEE. De todo modo, as causas da baixa incidência encontrada extrapolam os limites do presente trabalho e merecem ser objeto de estudo de pesquisas futuras.

Os dados mostram que a raça-etnia branca predominou com um pouco mais da metade da quantidade de alunos que realizaram a Prova Brasil da $4^{\mathrm{a}}$ série, em 2007. Isto porque, de 21 alunos que fizeram a prova, 12 se declararam com brancos. Com a junção da raça-etnia: preta e parda, verifica-se que é a segunda e de maior incidência, com 6 casos dentre os 21 . $\mathrm{Na}$ sequência, destaca-se a população que não declararam sua raça-etnia, com dois casos e apenas 
um que se declara como indígena. Ou seja, a cada sete alunos com necessidades educacionais especiais que fizeram a Prova Brasil (2007), quatro são da raça-etnia: branca, dois são da raçaetnia: preta/ parda e um de raça: não declarada e indígena.

A partir dos dados apresentados, somente oito dos 21 alunos que realizaram a prova encontram-se na faixa etária adequada para a série. Esses sujeitos apresentam as seguintes Necessidades Educacionais Especiais: deficiência auditiva, baixa visão, superdotação, transtornos globais do desenvolvimento e deficiência física. O restante dos alunos encontra-se em condição de defasagem idade-série.

No ano de 2007, os alunos da $4^{\mathrm{a}}$ série que realizaram a Prova Brasil responderam 22 questões de língua portuguesa e 22 questóes de matemática. Para a análise dos dados, é importante evidenciar que a média de cada bloco de prova será de 11 acertos (metade do número de questóes).

Para a elaboração da análise dos dados, os alunos foram agrupados por tipo de Necessidade Educacional Especial. O primeiro caso a ser analisado será de dois alunos, um com deficiência auditiva e outro com surdez. O aluno com deficiência auditiva apresentou desempenho abaixo da média em ambas as provas, o que chamou mais a atenção foi que o mesmo zerou a prova de língua portuguesa; já o aluno com surdez acertou metade das questóes (11 questôes) em ambas as provas. Os dois alunos com baixa-visão apresentaram notas acima da média em língua portuguesa, mas na prova de matemática, um obteve 12 acertos e o outro nove. Os três alunos com superdotação que fizeram a prova apresentaram notas superiores à média (12 questóes) na prova de língua portuguesa e tiveram bom desempenho na prova de matemática: um aluno com 16 acertos e os outros dois alunos com 19. Dos cinco alunos com transtornos globais do desenvolvimento, três fizeram menos de 12 acertos em língua portuguesa e quatro alunos realizaram menos da metade da prova de matemática. Já os alunos com deficiência física, dois fizeram mais do que 14 questóes em língua portuguesa e um tirou nota inferior à média (sete acertos). Com relação à prova de matemática, dois acertaram mais do 14 questóes na prova e um acertou sete questóes.

Ao agrupar os alunos com deficiências múltiplas e o aluno com deficiência física/ deficiência intelectual, nota-se que ambos obtiveram baixo rendimento em ambas as provas, sendo que o menor número de acertos em língua portuguesa foi cinco questóes e em matemática, apenas três. Ao analisar os quatro alunos com deficiência intelectual, nota-se que um desses alunos está sem nota em ambas as provas e há informaçóes suficientes para explicar tal ocorrência, já que este aluno está cadastrado como um aluno que fez a prova, mas que por algum motivo teve seus resultados zerados. Os demais alunos com deficiência intelectual que realizaram a prova, obtiveram baixo desempenho em ambas as provas, ou seja, nenhum destes ultrapassou a média de 12 acertos nas provas de língua portuguesa e matemática.

Ainda que desempenho dos alunos com NEE, especificamente daquelas decorrentes da deficiência intelectual, possa ser considerado baixo, de acordo com os critérios estipulados pela avaliação, vale destacar que neste grupo de alunos o desempenho não deve ser muito discrepante do restante do alunado do ensino regular, a ponto de justificar sua não participação. Além disso, entendemos que o baixo desempenho não pode ser analisado como limites do próprio aluno, inerentes à sua necessidade educacional especial, haja vista o entendimento 
das avaliaçóes em larga escala como instrumentos limitados no que se refere à averiguação do aprendizado (SASS; MINHOTO, 2011).

A Tabela 3 apresenta a caracterização dos alunos com Necessidades Educacionais Especiais que fizeram a Prova Brasil- 8a série, no município de Londrina (PR), no ano de 2007. Tabela 3 - Caracterização dos alunos com Necessidades Educacionais Especiais (NEEs) que realizaram a Prova Brasil na $8^{a}$ série.

\begin{tabular}{lccccc}
\hline NEE & SEXO & RAÇA & IDADE & \multicolumn{2}{c}{ DESEMPENHO } \\
& & & & Língua Portuguesa & Matemática \\
1. baixa visão & $\mathrm{M}$ & branca & 14 & 12 & 13 \\
2. def. intelectual & $\mathrm{M}$ & branca & 20 & 14 & 5 \\
3. def. física & $\mathrm{F}$ & branca & 33 & 23 & 5 \\
4. def. física & $\mathrm{M}$ & branca & 17 & 14 & 9 \\
5. def. intelectual & $\mathrm{M}$ & não decl. & 17 & 5 & 6 \\
\hline
\end{tabular}

Fonte: Elaboração própria com base nas informações extraídas dos microdados do Censo da Educação Básica e da Prova Brasil (MEC/INEP, 2007).

De um total de 21 alunos com Necessidades Educacionais Especiais, matriculados na $8^{a}$ série da rede pública, no município de Londrina (PR), no ano de 2007, somente cinco realizaram a prova. Destes cinco alunos, um apresenta baixa visão, dois apresentam deficiência intelectual e dois apresentam deficiência física.

De acordo com os dados do Censo Escolar (2007), dos 21 alunos com NEE presentes na $8^{\mathrm{a}}$ série no município de Londrina (PR), 13 eram do sexo masculino e oito do sexo feminino. Isto equivale a dizer que, aproximadamente, a cada cinco alunos com NEE, três são do sexo masculino e dois do sexo feminino. Entretanto, ao contrapor com os dados de quem realizou a Prova Brasil (2007), verifica-se que este número se modifica ainda mais, já que dos 5 alunos que realizaram a prova, apenas um é do sexo feminino.

No que se refere à raça-etnia, os 21 alunos com NEE estão distribuídos da seguinte forma: não declarada (um aluno), branca (14 alunos), preta (um aluno), parda (quatro alunos) e amarela (um aluno). Ou seja, para cada três alunos com Necessidades Educacionais Especiais dois eram brancos. No que se refere ao quesito: "com prova” esta proporção aumenta: todos os alunos da $8^{\mathrm{a}}$ série com Necessidades Educacionais Especiais que realizaram a prova são (declaram-se) brancos.

No que diz respeito à idade destes estudantes que realizaram a Prova Brasil, apenas um dos cinco alunos encontra-se em idade regular de 14 anos, sendo que este aluno apresenta baixa visão. Os demais se encontram com defasagens: há inclusive, casos em que a defasagem idade-série é de 19 anos, isto equivale a dizer que, encontram-se alunos de até 33 anos na $8^{\text {a }}$ série, no ano de 2007. Cabe salientar, que esses estudantes não estão matriculados na educação de jovens e adultos, mas sim no sistema público regular do município de Londrina (PR). Destes alunos com grande defasagem idade-série, dois apresentam deficiência física e dois deficiência intelectual. 
Merece destaque o fato destes adultos não estarem frequentando modalidades de ensino mais adequada à sua faixa-etária, como a Educação de Jovens e Adultos. Isso corrobora estudos como os desenvolvidos por Glat (1989) e Ferreira (1994), que indicam a intensa infantilização de adultos que apresentam alguma deficiência. Cabe questionar como se deu o processo de escolarização destes sujeitos e com quais justificativas pedagógicas se mantém adultos nestas condiçóes de ensino.

O desempenho dos estudantes na avaliação em larga escala- Prova Brasil, se dá, por meio de provas de língua portuguesa e matemática. No ano de 2007 , os alunos da $8^{\text {a }}$ série responderam a 26 questóes de língua portuguesa e 26 questóes de matemática. Para a análise dos dados, é importante destacar que a média de cada bloco de prova será de 13 acertos (metade do número de questóes).

O melhor desempenho foi de um aluno com deficiência física, com 23 acertos em língua portuguesa e 17 em matemática. Já o outro aluno com deficiência física, acertou mais da metade da prova de língua portuguesa e obteve desempenho abaixo da média em matemática, com nove acertos. $\mathrm{O}$ aluno com baixa visão obteve nota mediana em matemática e nota inferior à média em língua portuguesa, com 12 itens corretos. Dos dois alunos com deficiência intelectual, um obteve baixíssimo desempenho em ambas as matérias, com cinco respostas corretas na língua portuguesa e seis na matemática, já o outro ficou com nota acima da média em língua portuguesa (14 questóes) e com nota baixa em matemática (cinco questóes).

A tabela 4 a seguir apresenta a caracterização dos alunos com Necessidades Educacionais Especiais que fizeram o Exame Nacional do Ensino Médio (ENEM)- 3o ano do Ensino Médio, no município, em 2007.

Tabela 4 - Caracterização dos alunos com Necessidades Educacionais Especiais (NEEs) que realizaram o ENEM.

\begin{tabular}{lccccc}
\hline NEE & SEXO & RAÇA & IDADE & \multicolumn{2}{c}{ DESEMPENHO } \\
& & & & Quest. Objetivas & $\begin{array}{c}\text { Redaçáo } \\
\text { 1. Síndrome de Down }\end{array}$ \\
2. surdez & F & preta & 21 & 16 & em branco \\
3. surdez & F & branca & 19 & 16 & $60 \%$ \\
4. surdez & F & parda & 21 & 43 & em branco \\
5. surdez & F & parda & 19 & 24 & $38 \%$ \\
6. surdez & F & parda & 21 & 19 & $30,16 \%$ \\
7. surdez & F & branca & 19 & 19 & $19,05 \%$ \\
8. surdez & M & branca & 23 & 27 & $42,86 \%$ \\
9. surdez & F & branca & 18 & 19 & $30,16 \%$ \\
10. surdez & F & branca & 19 & 20 & $21,75 \%$ \\
\hline
\end{tabular}

Fonte: Elaboração própria com base nas informaçóes extraídas dos microdados do Censo da Educação Básica e da Prova Brasil (MEC/INEP, 2007). 
De um total de 13 alunos com NEE no 3a ano do Ensino Médio, no município de Londrina (PR), em 2007, 10 realizaram o ENEM. Dentre esses, nove alunos apresentavam surdez 5 e um Síndrome de Down.

Constata-se um dado interessante: ao contrário da $4^{\mathrm{a}}$ e $8^{\mathrm{a}}$ série do ensino fundamental, é notória a maior incidência de estudantes do sexo feminino (oito) em comparação ao sexo masculino (dois). Ao contrapor esses números com os dados do Censo Escolar (2007), verificase que de um total de 13 alunos matriculados no município de Londrina (PR), no 3o ano do Ensino Médio, nove são do sexo feminino e quatro do sexo masculino. Conclui-se, assim, que todos os alunos do sexo feminino realizaram a avaliação, em contrapartida somente a metade dos estudantes do sexo masculino fizeram o prova do ENEM (2007).

No quesito raça-etnia, assim como nas outras etapas de ensino ( $4^{\mathrm{a}}$ e $8^{\mathrm{a}}$ série), percebese uma maior incidência da raça-etnia branca, com seis dos 10 alunos que fizeram a prova. $\mathrm{Na}$ sequência, encontra-se a raça-etnia preta e parda, com quatro dos 10 estudantes. Isto significa que, de cada cinco alunos que realizaram o ENEM (2007), três são brancos e dois declaram-se negros ou pardos.

Ao cotejar tais dados com o do Censo Escolar (2007) dos 13 alunos com Necessidades Educacionais Especiais no município de Londrina (PR), havia sujeitos que não declaravam sua raça-etnia (dois), que se declaravam brancos (sete), negros (um) e pardos (três). Isto significa que quase todos os alunos brancos matriculados no município fizeram a prova (com exceção de um); já todos os alunos negros e pardos matriculados fizeram o Exame Nacional do Ensino Médio (ENEM) (2007).

Constata-se que nenhum dos alunos com Necessidades Educacionais Especiais que fizeram o Exame Nacional do Ensino Médio (ENEM) (2007) encontram-se na idade regular, isto é, com 17 anos. Há alunos com defasagem de um até seis anos idade-série. Metade dos alunos que fizeram a prova tem idade de 18 e 19 anos e a outra metade tem idade de 21 e 23 anos (dentre esses está um aluno com Síndrome de Down).

O desempenho na avaliação em larga escala - Exame Nacional do Ensino Médio (ENEM) (2007) se dá, como já foi dito anteriormente, por meio de 63 questóes objetivas e uma redação, com valor máximo de $100 \%$. Para a análise dos dados, vale mencionar que a média das questóes objetivas será de 31 acertos e a da redação 50\%.

Duas alunas que fizeram o Exame Nacional do Ensino Médio (ENEM) (2007) conseguiram atingir a média das questóes objetivas: uma delas possui Síndrome de Down e acertou 31 questóes; a outra é surda e respondeu de forma correta a 43 questóes. O desempenho dessas alunas foi o melhor dentre os 10 alunos com necessidades educacionais especiais que realizaram a avaliação. Dentro deste montante, três alunos responderam corretamente de 20 a 27 questóes, quatro acertaram de 16 a 19 itens e o aluno com a nota mais baixa acertou apenas 12 questóes objetivas.

\footnotetext{
${ }^{5}$ Os alunos surdos citados acima são todos matriculados no ILES- Instituto Londrinense de Educação para Surdos, escola especial para surdos, que está classificada no Data Escola Brasil como escola regular, com dependência administrativa estadual. Acesso em: (http://www.dataescolabrasil.inep.gov.br/dataEscolaBrasil/).
} 
Com relação à nota da redação, dois dos 10 alunos entregaram a prova em branco. Apenas um aluno com surdez tirou nota acima da média (60\% da prova) e o os outros sete alunos tiraram notas que variam de $19,05 \%$ até $45 \%$ da prova.

\subsection{ANO DE 2008}

O município de Londrina (PR), em 2008, contemplou um total de 120.227 matrículas, incluindo as três modalidades de ensino (regular, especial e educação de jovens e adultos). Deste total de matrículas 1.494 destinam-se a alunos com Necessidades Educacionais Especiais. Dentre os estudantes com Necessidades Educacionais Especiais nove encontram-se matriculados no $3^{\circ}$ ano do Ensino Médio e todos se encontravam na rede pública de ensino.

Assim como em 2007, quatro alunos da referida etapa de ensino estavam matriculados em uma escola especial exclusiva para surdos, o Instituto Londrinense de Educaçáo para Surdos (ILES), que está classificada no Censo Escolar com escola regular, como dependência administrativa estadual. Cabe destacar que foi descartado o único caso de duplicidade encontrado na avaliação do Exame Nacional do Ensino Médio (ENEM) (2008). Desse modo, será considerado apenas o contingente de oito alunos. Dentre esses, cinco alunos realizaram o Exame e três não participaram da avaliação.

A tabela 5 a seguir apresenta a caracterização dos alunos com Necessidades Educacionais Especiais que fizeram o Exame Nacional do Ensino Médio (ENEM) - 3o ano do Ensino Médio, no município, em 2008.

Tabela 5 - Caracterização dos alunos com Necessidades Educacionais Especiais (NEEs) que realizaram o ENEM.

\begin{tabular}{lccccc}
\hline NEE & SEXO & RAÇA & IDADE & \multicolumn{2}{c}{ DESEMPENHO } \\
1. def. física & M & branca & 18 & 30 & Redação \\
2. def. física & $\mathrm{M}$ & branca & 20 & 23 & $60 \%$ \\
3. surdez & $\mathrm{F}$ & branca & 19 & 15 & $47,5 \%$ \\
4. surdez & $\mathrm{F}$ & branca & 19 & 17 & $50 \%$ \\
5. def. visual & $\mathrm{F}$ & preta & 17 & 23 & $37,5 \%$ \\
\hline
\end{tabular}

Fonte: Elaboração própria com base nas informaçôes extraídas dos microdados do Censo da Educação Básica e do ENEM (MEC/INEP, 2008).

De um total amostral de oito alunos com NEE no 3o ano do Ensino Médio, no município de Londrina (PR), em 2008, cinco alunos realizaram o ENEM. Destes, cinco realizaram a prova; dois alunos são surdos ${ }^{6}$, dois apresentam deficiência física e um deficiência visual.

Dentre os cinco estudantes que realizaram o ENEM (2008), três são do sexo feminino e dois do sexo masculino. Ao contrapor esses números com os dados do Censo Escolar (2008),

\footnotetext{
${ }^{6} \mathrm{O}$ aluno surdo (aluno n. 4) citado acima está matriculado no ILES- Instituto Londrinense de Educação para Surdos, escola especial para surdos, que está classificada no Data Escola Brasil como escola regular, com dependência administrativa estadual. Acesso em: (http://www.dataescolabrasil.inep.gov.br/dataEscolaBrasil/).
} 
verifica-se que, dos oito alunos (descartando o único caso de duplicidade), quatro alunos são do sexo feminino e quatro são do sexo masculino.

No quesito raça-etnia, assim como na Prova Brasil e no ENEM do ano de 2007, percebe-se uma maior incidência da raça-etnia: branca, com quatro dos cinco alunos que fizeram a prova. Apenas um estudante da raça-etnia: preta fez a prova. Ao cotejar tais dados com o do Censo Escolar (2008), dos oito alunos com NEE no município de Londrina (PR) na referida etapa de ensino, haviam sujeitos com raça-etnia: branca (seis), preta (um) e parda (um). Isto significa que, dois a cada três alunos da raça-etnia: branca fizeram a prova (único estudante da raça-etnia: preta também participou do ENEM).

Dos estudantes com NEE que fizeram o ENEM (2008), somente um, com deficiência visual, encontra-se na idade regular, de 17 anos. A maior defasagem encontrada foi de três anos idade-série de um aluno com deficiência física. Dos outros três estudantes, dois estavam com 19 anos de idade (surdez) e um com deficiência física, com 18 anos.

O desempenho no ENEM (2008) se dá, por meio de 63 questóes objetivas e uma redação, com valor máximo de $100 \%$. Para a análise dos dados é importante destacar que a média das questóes objetivas será de 31 acertos e a da redação 50\%. Dos cinco estudantes, que fizeram a avaliação, nenhum conseguiu atingir a média das questóes objetivas: o melhor desempenho foi de um aluno com deficiência física, com 30 acertos das 63 questóes. $\mathrm{Na}$ sequência, dois estudantes obtiveram 23 acertos (deficiência visual e deficiência física) e o menor rendimento foi dos dois alunos com surdez, um com 15 acertos e o outro com 14 .

Já em relação à pontuação na redação, três alunos obtiveram nota acima da média. Dentre estes, um aluno com deficiência física (60\% da prova), um com surdez (50\% da prova) e um com deficiência visual (65\% da prova). Dos outros dois estudantes, que realizaram o ENEM (2008), um com deficiência física fez 47,5\% e um com surdez fez 37,5\% da prova.

Com relação ao ENEM nos anos de 2007 e 2008, cumpre destacar alguns aspectos.

Primeiro, o baixo índice de matrículas de alunos com NEE no Ensino Médio. Indicadores educacionais da Educação Básica, indicam um afunilamento do número de matrículas entre o Ensino Fundamental e o Ensino Médio. Meletti e Bueno (2011) mostram que, no Brasil, em 2009, as matrículas no Ensino Médio correspondiam a 25,9\% das do Ensino Fundamental. Por outro lado, no mesmo ano, as 19.107 matrículas de alunos com NEE no Ensino Médio correspondiam a 5,6\%. Isso sustenta a análise de que o problema de acesso ao Ensino Médio se agrava em se tratando dos alunos com NEE, visto que a cada 100, apenas cinco ingressam nesta etapa de ensino.

Segundo, a participação dos alunos com NEE no ENEM, ainda que em maior proporção que nos outros exames analisados, pode ser considerada baixa. O ENEM é utilizado como medida facilitadora da continuidade dos estudos, seja no ensino superior, seja no profissionalizante. $\mathrm{O}$ fato ou de não chegar ao Ensino Médio ou, se chegar, não participar do exame nacional, indica uma barreira no processo de inclusão da pessoa com NEE no ensino regular. Mais uma vez, os dados oficiais do poder público evidenciam a precariedade do processo de escolarização desta população. 


\section{Consideraçóes}

A análise da participação de alunos com NEE nas avaliações em larga escala do Ensino Fundamental e do Ensino Médio apresentou alguns aspectos que merecem nossa atenção: o baixo número de matrículas desta população nas séries em as provas são aplicadas; sua pequena participação nos exames nacionais; a defasagem idade-série, principalmente na 8 a série; a maior incidência de alunos do sexo masculino e que se declararam brancos; desempenho mediano, que não pode ser utilizado como justificativa para a não participação.

Evidenciou-se a necessidade de investigaçóes futuras que ampliem as análises aqui tecidas, considerando as condiçóes efetivas de escolarização desta população no ensino regular. Todas as informaçóes aqui apresentadas e analisadas apontam para a complexidade e dificuldade da implementação de um sistema de ensino inclusivo.

\section{REFERÊNCIAS}

BRASIL. Ministério da Educação. Instituto Nacional de Estudos e Pesquisas Educacionais Anísio Teixeira - INEP. SAEB - 2005. Disponível em: http:/www.inep.gov.br/básica /levantamentos/ microdados.asc.. Acesso em: 20 fev. 2012.

. Ministério da Educação. Instituto Nacional de Estudos e Pesquisas Educacionais Anísio Teixeira - INEP. Censo Escolar da Educação Básica - 2007. Disponível em: http://www.inep.gov.br/ basica/levantamentos/microdados.asc. Acesso em: 15 fev. 2012.

. Ministério da Educação. Instituto Nacional de Estudos e Pesquisas Educacionais Anísio Teixeira - INEP. Prova Brasil - 2007. Disponível em: http://www.inep.gov.br/básica /levantamentos/ microdados.asc.. Acesso em: 20 fev. 2012.

. Ministério da Educação. Instituto Nacional de Estudos e Pesquisas Educacionais Anísio Teixeira- INEP. Enem - 2007. Disponível em: http://www.inep.gov.br/básica/ levantamentos/ microdados.asc.. Acesso em: 22 fev. 2012.

- Ministério da Educação. Instituto Nacional de Estudos e Pesquisas Educacionais Anísio Teixeira - INEP. Censo Escolar da Educação Básica - 2008. Disponível em: http://www.inep.gov.br/ basica/levantamentos/microdados.asc.. Acesso em: 16 fev. 2012.

. Ministério da Educação. Instituto Nacional de Estudos e Pesquisas Educacionais Anísio Teixeira- INEP. Enem - 2008. Disponível em: http://www.inep.gov.br/básica/ levantamentos/ microdados.asc.. Acesso em: 22 fev. 2012.

. Ministério da Educação. Instituto Nacional de Estudos e Pesquisas Educacionais Anísio Teixeira- INEP. Enem - 2009. Disponível em: http://www.inep.gov.br/básica/ levantamentos/ microdados.asc.. Acesso em: 22 fev. 2012.

- Ministério da Educação. Instituto Nacional de Estudos e Pesquisas Educacionais Anísio Teixeira- INEP. Enem - 2010. Disponível em: http://www.inep.gov.br/básica/ levantamentos/ microdados.asc.. Acesso em: 22 fev. 2012.

. Ministério da Educação. Instituto Nacional de Estudos e Pesquisas Educacionais Anísio Teixeira (MEC/ Inep). 2012. Disponível em:<http://portal.inep.gov.br/> Acesso em: 13 fev.2012.

. IBGE. Censo Demográfico 2010: características gerais da população. Rio de Janeiro: IBGE,

2012. 
FERREIRA, M. C. C. A prática educativa e a concepção de desenvolvimento psicológico de alunos com deficiência mental. Tese (Doutorado em Educação) - Faculdade de Educação, Universidade Estadual de Campinas, Campinas, 1994.

GLAT, R. Somos iguais a vocês: depoimentos de mulheres com deficiência mental. Rio de Janeiro: Agir, 1989.

JANNUZZI, P. M. Indicadores Sociais no Brasil: Conceitos, fontes de dados e aplicaçóes. Campinas: Alínea/PUC-Campinas, 2006.

KASSAR, M. C. M.; MELETTI, S. M. F. Análises de Possiveis Impactos do Programa Educação Inclusiva: Direito à Diversidade. Ciências Humanas e Sociais em Revista, RJ, EDUR, v. 34, n. 12, jan / jun, p. 49-63, 2012.

MELETTI, S. M. F.; BUENO, J. G. S. Os indicadores educacionais como meio de avaliação das políticas de educação especial no Brasil - 2000/2009. In: Bueno, J. G. S.. (Org.). Educação especial brasileira: questóes conceituais e de atualidade. 1ed. São Paulo: EDUC, p. 159-182, 2011.

SASS, O.; MINHOTO, M. A. P. Indicadores e educação no Brasil: a avaliação como tecnologia. Revista de Teoria Crítica. v. 2, p. 232-252, 2011.

ZANARDINI, J. B. Ontologia e Avaliação da Educação Básica no Brasil (1990-2007). 2008. $209 f$. Tese (Doutorado em Educaçáo) - Programa de Pós-Graduaçáo em Educação, Centro de Ciências da Educação, Universidade Federal de Santa Catarina, Florianópolis, 2008.

Recebido em: 10/04/2013

Reformulado em: 16/10/2013

Aprovado em: 02/12/2013 
SILVA, M. C. V. \& MELETTI, S. M. F. 